\title{
The miticide thymol in combination with trace levels of the neonicotinoid imidacloprid reduces visual learning performance in honey bees (Apis mellifera)
}

\author{
Théotime Colin ${ }^{1}$, Jenny A. Plath ${ }^{1,2}$, Simon Klein ${ }^{1,3}$, Peta Vine ${ }^{1}$, Jean-Marc Devaud ${ }^{3}$, \\ Mathieu Lihoreau ${ }^{3}$, William G. MeIKle ${ }^{4}$, Andrew B. Barron ${ }^{1}$ \\ ${ }^{1}$ Department of Biological Sciences, Macquarie University, Sydney, NSW, Australia \\ ${ }^{2}$ Department of Biology and Animal Physiology, University of Kassel, 34132, Kassel, Germany \\ ${ }^{3}$ Research Center on Animal Cognition (CRCA), Center for Integrative Biology (CBI), CNRS, Paul Sabatier University, \\ Toulouse, France \\ ${ }^{4}$ Carl Hayden Bee Research Center, USDA-ARS, Tucson, AZ, USA
}

Received 30 May 2019 - Revised 28 November 2019 - Accepted 15 January 2020

\begin{abstract}
Despite growing concerns over the impacts of agricultural pesticides on honey bee health, miticides (a group of pesticides used within hives to kill bee parasites) have received little attention. We know very little about how miticides might affect bee cognition, particularly in interaction with other known stressors, such as crop insecticides. Visual learning is essential for foraging bees to find their way to flowers, recognize them, and fly back to the nest. Using a standardized aversive visual conditioning assay, we tested how field exposure to three pesticides affects visual learning in European honey bees (Apis mellifera). Our pesticides were two common miticides, thymol in the commercial formulation Apiguard ${ }^{\circledR}$ and tau-fluvalinate in the formulation Apistan ${ }^{\circledR}$ and one neonicotinoid, imidacloprid. We found no effect of miticides alone, nor of field-relevant doses of imidacloprid alone, but bees exposed to both thymol and imidacloprid showed reduced performance in the visual learning assay.
\end{abstract}

thymol / Varroa destructor / tau-fluvalinate / imidacloprid / acaricide

\section{INTRODUCTION}

There is increasing awareness that agrochemical stressors of bees can harm learning and memory at sublethal levels, thus reducing foraging effectiveness and survival (Klein et al. 2017). In agriculturally intensive

Electronic supplementary material The online version of this article (https://doi.org/10.1007/s13592-020-00737-6) contains supplementary material, which is available to authorized users.

Corresponding author: A. Barron,

Andrew.barron@mq.edu.au

Théotime Colin, Jenny A. Plath and Simon Klein contributed equally to this work.

Manuscript editor: Monique Gauthier environments, bees are rarely exposed to a single agrochemical in isolation, and there is growing concern that agrochemical stressors might interact (Meikle et al. 2016; Sgolastra et al. 2018; Calatayud-Vernich et al. 2018; Tihelka 2018; Prado et al. 2019; Colin et al. 2019a). Most research has focused on the impacts of pesticides used on crops on European honey bees (Apis mellifera), but honey bees are also frequently exposed to miticides used within hives to control the parasitic mite Varroa destructor (Mullin et al. 2010; Tihelka 2018). Here, we assessed whether miticides can affect bee visual learning, and whether effects are increased if a miticide cooccurs with traces of another pesticide. 
Varroa destructor is considered perhaps the most damaging pest affecting the beekeeping industry (Ratnieks and Carreck 2010). This mite feeds on larvae and adult bees, which causes malformations, sickness, and the transmission of many diseases within and between colonies (Wallner and Fries 2003; Boecking and Spivak 1999; Le Conte et al. 2010; Rosenkranz et al. 2010). Varroa destructor is considered a significant factor driving a global rise in honey bee colony failure rates (Ratnieks and Carreck 2010) and is found in all countries where Apis mellifera is present with the exception of Australia and a few islands.

In-hive treatments known as miticides or acaricides are commonly used to control $V$. destructor, but the mite has evolved resistance to several of these miticides, which has reduced the options for control (Tihelka 2018). In addition, previous research has demonstrated negative effects of two common miticides, coumaphos and tau-fluvalinate, on honey bee survival (Berry et al. 2013), as well as queen body weight and longevity (tau-fluvalinate, Haarmann et al. 2002). Tau-fluvalinate, commercialized as Apistan $囚$, is a synthetic pyrethroid (Davies et al. 2007) acting as an arthropod neuron excitotoxin which prevents the closure of voltagegated sodium channels of axonal membranes, leading to prolonged membrane depolarization and thus to paralysis or death (Ray and Fry 2006). Taufluvalinate suppresses neuron excitability in the adult bee brain (Zhou et al. 2011) and impairs olfactory memory (Frost et al. 2013). Perhaps because of concerns related to these side effects, there has been an increase in alternative miticide treatments such as essential oils and organic acids (Mondet et al. 2011), which are commonly perceived to be safer for bees (Dietemann et al. 2012). Miticide use is unnecessary in Australia where Varroa destructor is absent. This provides Australia with a unique opportunity to test the effects of miticides on bees without a rise in $V$. destructor populations in untreated control groups confounding the results.

Thymol is a plant allelochemical commonly used for the control of $V$. destructor (Mondet et al. 2011), particularly the commercial formulation Apiguard $®$ in which it is mixed with a slowrelease gel. The mode of action of thymol on mites is not well understood, but it is believed that thymol interferes with GABA-ergic signalling in the central nervous system (Price and Lummis 2014). GABA is an important neurotransmitter for both mites and insects, and hence there are legitimate concerns that thymol also affects honey bees. For example, Apilife $\operatorname{Var} \AA$, a commercial formulation of thymol, eucalyptus oil, camphor, and levomenthol, is known to impair olfactory memory and phototactic response in bees shortly after its introduction in the hive (Carayon et al. 2014; Alayrangues et al. 2016; Bonnafé et al. 2017). In this study, we compared the effects of two miticide treatments: the Apiguard $®$ formulation of thymol and the Apistan $®$ formulation of tau-fluvalinate on honey bee visual learning.

In intensive agricultural environments, bees are exposed to pesticide contaminants that can accumulate inside the hive (Mullin et al. 2010; Alburaki et al. 2018). There is now enormous concern regarding the effects of pesticide contaminants on honey bees, especially neonicotinoids (Sánchez-Bayo et al. 2016; Tsvetkov et al. 2017; Lu et al. 2012; Sgolastra et al. 2017; Mitchell et al. 2017; Woodcock et al. 2017; Henry et al. 2012; Tosi et al. 2017; Forfert et al. 2017; Colin et al. 2019a; Colin et al. 2019b). Imidacloprid is the most commonly used neonicotinoid on crops (Simon-Delso et al. 2015) and has been found in $51 \%$ of honey samples worldwide (Mitchell et al. 2017). Because honey bee colonies in agricultural environments may be exposed to both miticides and pesticides, here we also explored whether potential deleterious effects of thymol on visual learning could be increased by simultaneous exposure to trace levels of the neonicotinoid insecticide imidacloprid.

Learning of colour is vital for bees to distinguish the features of profitable flowers, and to detect natural enemies. To quantify colour learning performance, we used the Automated Performance Index System (APIS) as an aversive visual conditioning assay, which allows automated tracking of the bee's responses to visual stimuli (Kirkerud et al. 2013). The assay provides a robust and simple measure of rate and degree of visual learning in honey bees. In our first experiment, we compared visual learning and memory performance of bees exposed to commercial miticide formulations of tau-fluvalinate and thymol miticides and untreated controls. In our second 
experiment, we chose to further investigate the effect of thymol, because of recent reports of its effects on olfactory memory and bee colonies (Tihelka 2018; Colin et al. 2019a; Colin et al. 2019c; Bonnafé et al. 2017) and compared visual learning performance of bees exposed to either thymol, a trace level of imidacloprid, or both substances together and untreated controls.

\section{MATERIALS AND METHODS}

\subsection{Colony history}

Honey bees were of a standard commercial strain available in Australia, usually referred to as Apis mellifera derived from a "Golden Italian" strain. All bees were sourced from the Macquarie University Research Apiary. Colonies were housed in standard hives commonly referred to as eight-frames two-box Langstroth hives of a volume of about 76 L. Forager bees were collected when leaving the hive, using a hand-held bee vacuum device (BioQuip Products, Inc., CA, USA).

\subsection{The APIS visual learning assay}

The APIS assay chamber was developed and built by the University of Konstanz (Kirkerud et al. 2013). In brief: APIS is a small chamber equipped with coloured LEDs to display fields of colour. The floor of the chamber can be electrified to deliver weak electric shocks paired with specific colours. APIS specifications and use are fully described in Plath et al. (2017). The APIS chamber can be illuminated with light fields varying in wavelength and intensity: blue ( $\lambda=465 \mathrm{~nm}$; luminous intensity, $105 \mathrm{mcd})$ or green $(\lambda=525 \mathrm{~nm}$; luminous intensity, $119 \mathrm{mcd}$ ). It is equipped with an electrifiable grid to deliver pulses of electric shock (10 V, $4 \mathrm{~Hz}, 100 \mathrm{~ms})$ to the bee, and with infrared sensors to automatically track the bee's movement. The position of a bee moving freely within the chamber is continuously recorded by means of infrared sensors. Tracking the bee's position in the chamber indicates the extent to which a bee has learned to avoid a colour field associated with shock. Shock and light delivery were automated by custom software depending on the position of the bee in the chamber. Blue light always illuminated the half of the chamber in which the bee was located at light-onset and green light, the other half. In preliminary experiments, no colour preference was found for either blue or green (Kirkerud et al. 2013; Plath et al. 2017).

Prior to each assay, single bees were captured and isolated for 10 to $15 \mathrm{~min}$ in the dark at approximately $24{ }^{\circ} \mathrm{C}$ in $50-\mathrm{mL}$ Falcon ${ }^{\mathrm{TM}}$ conical centrifuge tubes pierced with a pin to allow respiration before their introduction to the chambers. The chamber was cleaned with $70 \%$ ethanol solution and left to air dry to remove traces of alarm pheromones, known to impair learning (Urlacher et al. 2010). One bee was then placed into each chamber and left for $10 \mathrm{~min}$ in the dark for it to acclimatize to the chambers. Since foragers were selected randomly, information about age and foraging experience is unknown. These factors are expected to be randomized across treatments.

Each assay was composed of nine trainings, during which bees received an electric shock whenever they walk on the blue side of the chamber, followed by one test where the time spent in the blue side of the chamber was measured and bees do not receive any electric shock. The nine trainings were separated by $30 \mathrm{~s}$ of darkness. The chamber was illuminated for $14 \mathrm{~s}$ during each training, which comprised of a 3-s non-shock period, followed by $11 \mathrm{~s}$ of shock pulses delivered whenever a bee was situated in the blue side of the chamber. Shock pulses stopped whenever the bee was located in the green side of the chamber.

Following a 30-s delay, the bee was given the test of $14 \mathrm{~s}$ of illumination without shocks to determine the post-training response to blue and green light fields. As in the trainings, the test began with blue light illuminating the half of the chamber in which the bee was located. Because the position of the bees is measured by infrared sensors with no input from the observer, this assay can be considered blind.

\subsection{Experiments}

We ran two experiments (see below). The number of bees tested in each treatment group is summarized in Table I and the dates at which bees 
were collected are available in Supplementary Table 1 along with the Performance Index data for the test. The sequence of bees selected from treatment colonies was randomized and equal numbers of bees from all colonies were tested each sampling day.

\subsubsection{Experiment 1: Comparing visual learning performance of bees treated with thymol, tau-fluvalinate, or untreated controls}

Bees were sourced from six colonies. Two colonies were treated with thymol using Apiguard $\AA$ trays containing $25 \%$ thymol weight to weight (12.5 g per tray, Vita Europe Ltd., Basingstoke, UK) and two other colonies with tau-fluvalinate using Apistan ${ }^{\circledR}$ strips containing $10.3 \%$ of tau-fluvalinate weight to weight (824 mg per strip, Vita Europe Ltd., Basingstoke, UK). The final two colonies were untreated control colonies. Both miticides were applied following suppliers' instructions. Two Apistan ${ }^{\circledR}$ plastic strips were placed in each of the tau-fluvalinatetreated colonies, between two brood frames, for a total duration of 6 weeks before they were removed. Tau-fluvalinate is known to be found in honey at low concentrations even several months after the removal of the plastic strips so the actual duration of the exposure may have been longer than 6 weeks (Tsigouri et al. 2001). One Apiguard® gel container was placed on top of the top-box frames of each of the thymol-treated colonies for 2 weeks and renewed after 2 weeks for another 2 weeks. Thymol containers were thus present in the hive for a total duration of 4 weeks, but the exposure duration to thymol was likely longer because thymol is known to remain present in the hives at high concentrations after the end of the treatments (e.g. Meikle et al. 2016; Colin et al. 2019a).

Treatments started on 1 February 2016. Weekly hive inspections were performed to check for the presence of a queen and eggs. We started testing the bees 6 weeks after the beginning of the treatment, on 14 March 2016, in order to test foragers that were exposed to the miticides during their development or early adult life (about 21 days for development and 2 weeks for the transition from hive bees to foragers, Winston 1991). The experiment lasted for 19 days, from 14 March 2016 to 1 April 2016.

\subsubsection{Experiment 2: Comparing visual learning performance of bees treated with thymol and/or imidacloprid}

Here, we focused on thymol as a miticide because of its demonstrated effects on olfactory memory and phototaxis (Carayon et al. 2014; Alayrangues et al. 2016; Bonnafé et al. 2017). Bees were sourced from sixteen colonies used in Colin et al. (2019a). Four colonies were treated with thymol using Apiguard ${ }^{\circledR}$ (Vita Europe Ltd., Basingstoke, UK), four other colonies with imidacloprid Pestanal ${ }^{\circledR}$ (Sigma-Aldrich, CAS no. 138261-41-3), and four other colonies with a combination of Apiguard ${ }^{\circledR}$ and imidacloprid. The final four colonies were control colonies. Apiguard ${ }^{\circledR}$ was applied as in Experiment 1. Imidacloprid was fed to the bees in a 50:50 sugar to water mass syrup solution containing $5 \mathrm{ppb}$ imidacloprid solution as described in Meikle et al. (2016) over six consecutive weeks using in-hive frame feeders. This corresponds to the trace amounts of imidacloprid that honey bees are commonly exposed to when they forage on treated crops such as canola (Bonmatin et al. 2005). Pesticide analysis performed on the same colonies by Colin et al. (2019a) showed that the imidacloprid exposure was effective. Briefly, imidacloprid was detected during the treatment in bees from 7 of the 8 colonies exposed to imidacloprid at an average concentration of $0.71 \mu \mathrm{g} / \mathrm{kg}$ per bee $(\mathrm{SD}=0.51)$, and contamination was found in 1 of the 4 untreated control colonies at the dose of $0.22 \mu \mathrm{g} / \mathrm{kg}$ per bee. This colony was kept in the untreated group as this small amount could have resulted from contamination of the samples and not the colony. No contamination was found in the thymol group.

Treatments started on 19 January 2017. We started testing the bees 6 weeks after the beginning of the treatment, on 2 March 2017. The experiment lasted for 10 days (2 March 2017 to 12 March 2017). 
Table I. Number of colonies sampled, number of bees tested and number of bees retained for data analysis after exclusion of abnormally slow bees (average speed less than $2 \mathrm{~cm} / \mathrm{s}$ ).

\begin{tabular}{|c|c|c|c|c|c|c|c|}
\hline & \multicolumn{3}{|c|}{ Experiment 1} & \multicolumn{4}{|c|}{ Experiment 2} \\
\hline & Control & $\begin{array}{c}\text { Tau- } \\
\text { fluvalinate }\end{array}$ & Thymol & Control & Thymol & Imidacloprid & $\begin{array}{l}\text { Imidacloprid } \\
+ \text { thymol }\end{array}$ \\
\hline Number of hives & 2 & 2 & 2 & 4 & 4 & 4 & 4 \\
\hline Number of bees & 40 & 39 & 34 & 37 & 38 & 33 & 35 \\
\hline $\begin{array}{l}\text { Number of bees after } \\
\text { exclusion of slow bees }\end{array}$ & 36 & 28 & 31 & 31 & 35 & 30 & 30 \\
\hline
\end{tabular}

\subsection{Statistical analyses}

Analyses were adapted from Plath et al. (2017). We used a Performance Index (PI) as a metric showing the learning performance of the bees:

$\mathrm{PI}=\frac{t(\text { green })-t(\text { blue })}{t(\text { green })+t(\text { blue })}$

where $t$ (green) is the time spent on the green (non-shocked) side of the chamber, and $t$ (blue) is the time spent on the blue (shocked) side of the chamber. The Performance Index varies between -1 and 1 , where the positive values indicate that the bee spent more time in the non-shocked side that on the shocked side. Negative values indicate the opposite. A bee that has learned the association between the blue light and the shocks is expected to run away from the blue side shortly after light onset and avoid returning to the blue side, and thus has high Performance Index values. By contrast, a bee that has not learned the association is expected to spend equal amounts of time on each side or more time on the blue side, and thus has low Performance Index values.

Bees moving at an average speed of less than $2 \mathrm{~cm} / \mathrm{s}$ were excluded from the analyses (Table I): since learning is demonstrated by the movement of the bee, at less than this speed, it is difficult to demonstrate learning of the association between shocks and colours. Three to 11 bees were excluded per group based on this criterion. Although these numbers are too small to perform a formal statistical analysis, we believe they are unlikely to affect the results or reflect a significant effect of miticides on bee locomotion.

All analyses were conducted in R v3.5.0 ( $R$ Core Team 2018). Figures were made with ggplot2 v3.1.0 (Wickham 2016) and cowplot v0.9.4 (Wilke 2019). The performance indices and speed of the bees were analysed for the test only when no electric shock accompanies the blue light. We tested whether bees in the control groups learnt to avoid the colour associated to the electric shock with a one-sample Mann and Whitney test. We set $\mu=0$ the value of the Performance Index when a bee is not spending more time in the green than in the blue zone. The performance indices of the treatment groups were compared using mixed-effect ANOVAs with the function lmer() from the lme4 v1.1 package (Bates et al. 2015). Pairwise contrasts were performed with the function pairs() from the emmeans v1.3.0 package (Lenth 2018). Separate ANOVAs were built for each experiment, with the Performance Index or the average speed of the bee during the test as the quantitative outcome, the treatment as the categorical explanatory variable, and the colony of origin as a random factor. Pairwise comparisons were obtained between the control group and the other treatment groups.

The Performance Index is shown in Figures 1a and $2 \mathrm{a}$ for the trainings but these data were not analysed as we expected the Performance Index to be low and the results noisy, due to the bee's agitated state following electric shocks. 


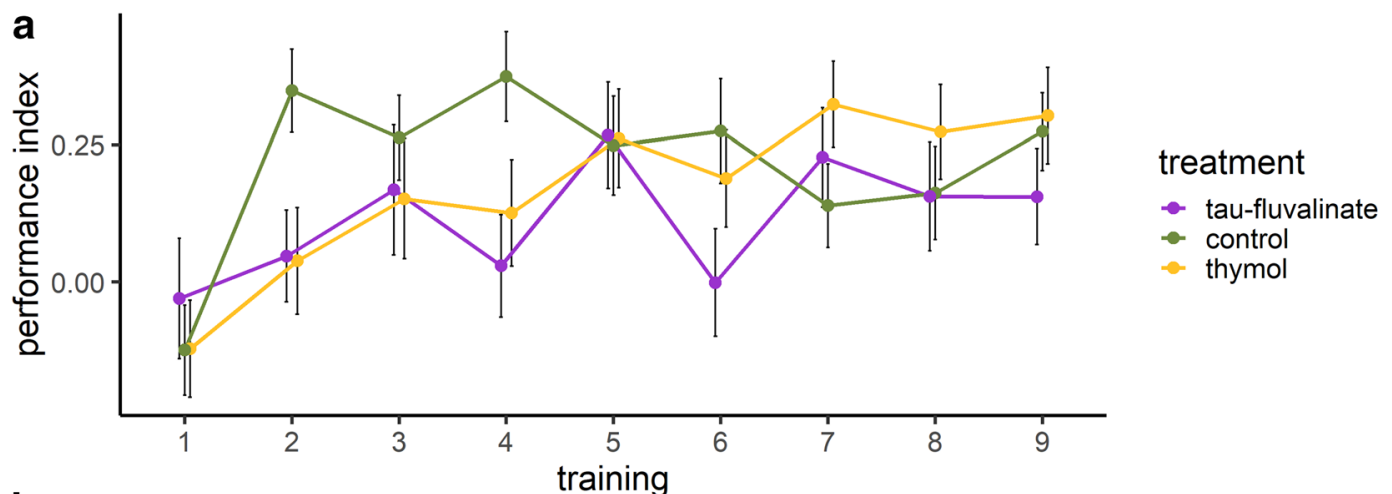

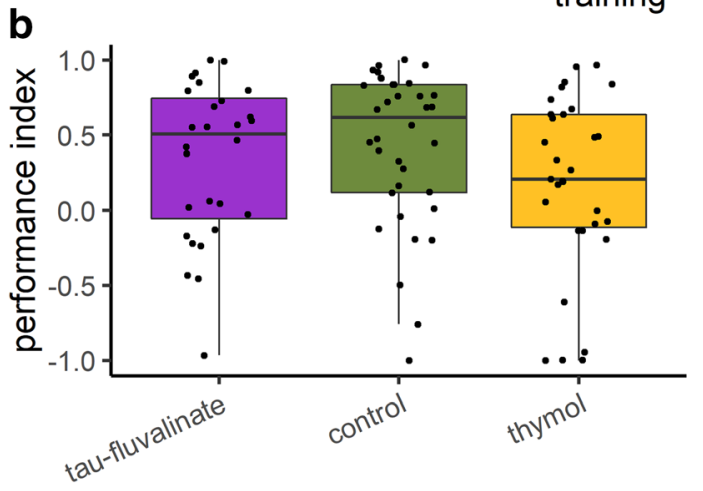

test

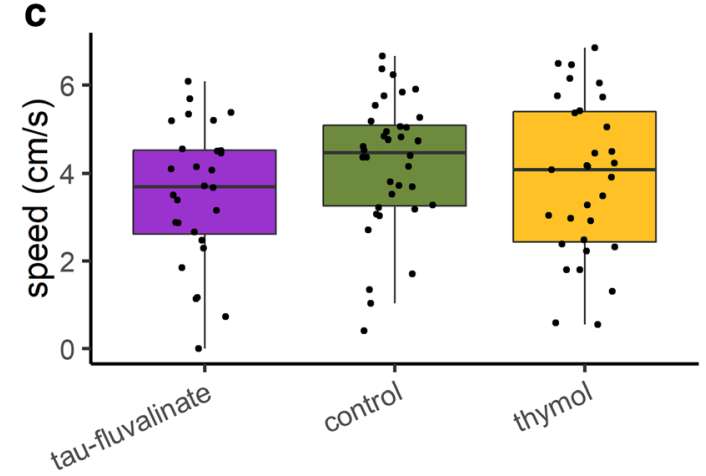

test

Figure 1. Visual learning performances of bees from colonies treated with thymol, tau-fluvalinate, or untreated controls. a Performance Index of the bees during the nine trainings (mean $\pm \mathrm{SE}$ ). On average, bees were able to obtain a positive Performance Index from the second training forward. b Performance Index during the test. c Individual speed during the test. For $\mathbf{b}, \mathbf{c}$, boxes represent the first and third quartiles and the thick line the median, whiskers extend to $1.5 \mathrm{x}$ the interquartile distance.

\section{RESULTS}

\subsection{Experiment 1: Visual learning performance of bees treated with thymol, tau-fluvalinate, and controls did not differ}

Bees in all groups were on average able to reach a positive Performance Index from the second training (Figure 1a), indicating that they spent less time in the shock-associated colour field than in the non-shocked colour field. During the test, bees in the control group significantly avoided the blue zone (Wilcoxon signed rank test, mean $=0.43, \mu=0, p$ value $=$ $1.98 \mathrm{e}-6)$. During the test, there was no significant difference in the performances between the control group (mean $=0.43, \mathrm{SE}=0.08)$ and either the tau-fluvalinate or the thymol groups (tau-fluvalinate: mean $=0.33, \mathrm{SE}=0.10, p$ value $=0.58$; thymol: mean $=0.17, \mathrm{SE}=0.11, p$ value $=0.21)$ (Figure $1 \mathrm{~b}$ ). There was also no difference in speed of movement in the assay between the control group (mean $=4.20 \mathrm{~cm} / \mathrm{s}$, $\mathrm{SE}=0.25 \mathrm{~cm} / \mathrm{s}$ ) and the tau-fluvalinate and thymol groups (tau-fluvalinate: mean = $3.53 \mathrm{~cm} / \mathrm{s}, \mathrm{SE}=0.30 \mathrm{~cm} / \mathrm{s}, p$ value $=0.20$; thymol: mean $=3.87 \mathrm{~cm} / \mathrm{s}, \mathrm{SE}=0.321 \mathrm{~cm} / \mathrm{s}$, $p$ value $=0.48)($ Figure $1 \mathrm{c})$. Hence, treatment with thymol or tau-fluvalinate alone did not affect performance.

\subsection{Experiment 2: Combined treatment of thymol and imidacloprid impaired visual learning performance}

Bees in all groups were on average able to reach a positive Performance Index from the 


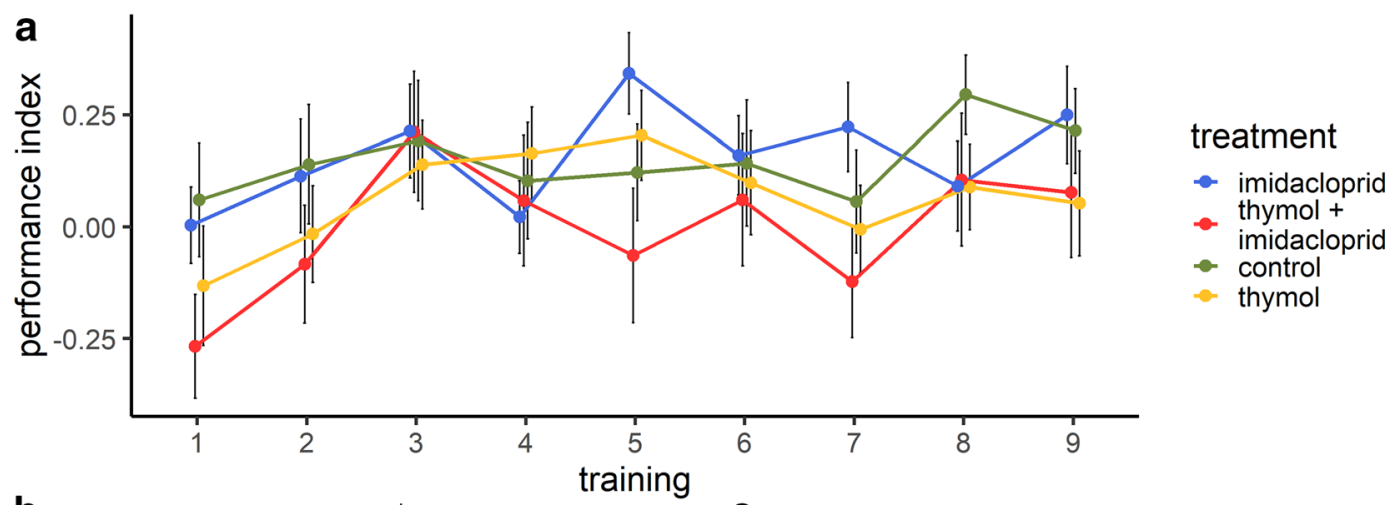

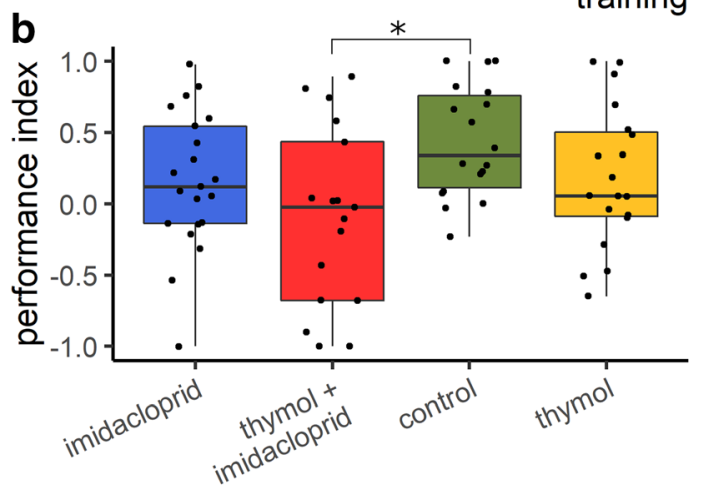

test

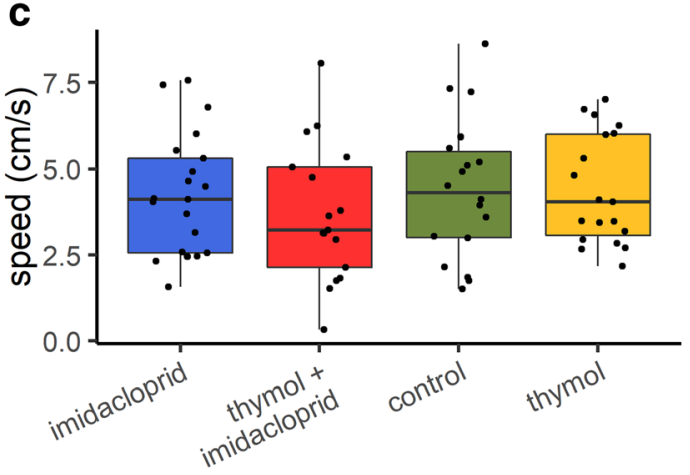

test

Figure 2. Visual learning performances of bees from colonies treated with thymol and/or imidacloprid or untreated controls. a Performance Index of the bees during the nine trainings (mean \pm SE). On average, bees were able to obtain a positive Performance Index from the third training forward. b Performance Index during the test. c Individual speed during the test. "*” indicates significance at $\alpha<0.05$.

third training forward (Figure 2a). During the test, bees in the control group significantly avoided the blue zone (Wilcoxon signed rank test, mean $=0.44, \mu=0, p$ value $=0.004$ ).

In the test, there was no significant difference in the performances between the control group (mean $=0.44, \mathrm{SE}=0.09$ ) and the imidacloprid or the thymol groups (imidacloprid: mean $=0.16$, $\mathrm{SE}=0.11, p$ value $=0.145$; thymol: mean $=$ $0.19, \mathrm{SE}=0.11, p$ value $=0.188)$, but bees in the combined thymol and imidacloprid treatment group had an average Performance Index that was slightly less than zero and significantly lower than the control group (combined thymol and imidacloprid: mean $=-0.09, \mathrm{SE}=0.15, p$ value $=$ 0.016) (Figure 2b). This suggests that visual learning in this group was impaired, both in absolute terms and relative to the performance of the control group. There were no significant differences in the movement speed between the control group $($ mean $=4.41 \mathrm{~cm} / \mathrm{s}, \mathrm{SE}=0.48 \mathrm{~cm} / \mathrm{s}$ ) and the imidacloprid, thymol, or combined thymol and imidacloprid treatment groups (imidacloprid: mean $=4.2 \mathrm{~cm} / \mathrm{s}, \mathrm{SE}=0.38 \mathrm{~cm} / \mathrm{s}$, $p$ value $=0.754 ;$ thymol: mean $=4.41 \mathrm{~cm} / \mathrm{s}, \mathrm{SE}=$ $0.37 \mathrm{~cm} / \mathrm{s}, p$ value $=0.997$; combined thymol and imidacloprid: mean $=3.7 \mathrm{~cm} / \mathrm{s}, \mathrm{SE}=0.49 \mathrm{~cm} / \mathrm{s}, p$ value $=0.31)$ (Figure $2 \mathrm{c})$, providing no evidence that differences in learning Performance Index were simply due to differences in ability to move in the assay. Thus, combined exposure to thymol and imidacloprid impaired performance.

\section{DISCUSSION}

Here, we investigated if visual learning of honey bees was affected by colony treatments with miticides and pesticides. We did not find 
any evidence that exposure to either miticide, thymol, or tau-fluvalinate or to the trace amounts of the insecticide imidacloprid during the development and early life of honey bees impaired aversive visual learning when they were applied alone. However, when thymol was applied in combination with imidacloprid, bee workers were not able to associate a specific colour to a weak electrical shock. This interaction provides evidence that accumulating stressors can interact and affect bee behaviours, which could weaken honey bee colonies.

Little is known about the effects of thymol on honey bees and it is unclear why thymol and imidacloprid only significantly affected learning in European honey bees when they were applied together. It has been suggested that thymol acts as an agonist of a GABA receptor in the brains of insects (Price et al. 2014), but imidacloprid mainly binds to neuronal nicotinic acetylcholine receptors (Gauthier 2010). One study however suggests that imidacloprid may be an antagonist of a GABA receptor in insect brains (Taylor-Wells et al. 2015). Therefore, these compounds are not expected to act in the same way and their interactive or additive effects may be complex.

The combined effect of thymol and imidacloprid on honey bees is worrying. Miticides, neonicotinoids, and many other types of pesticides are found together in hives located in agricultural landscapes (Tosi et al. 2018) and are known to accumulate in pollen, honey, and wax (Mullin et al. 2010; Boyle and Sheppard 2017). Our finding highlights the need for more studies on the effect of combined pesticide exposure on the health and productivity of bee colonies. Miticides in particular are sometimes applied together or successively (Brodschneider et al. 2019) and residues can accumulate so that more than one miticide residue is often found in a colony (Mullin et al. 2010), and are commercially available as complex mixtures (Apilife $\operatorname{Var}{ }^{\circledR}$ is a widely used commercial formulation of thymol, eucalyptus oil, camphor, and levomenthol). Additionally, successive treatments can also cause miticides to accumulate in bee products (Bogdanov et al. 1998; Mullin et al. 2010).

There has been little rigorous investigation of miticide compounds alone and even less in combination. A previous study found that Apilife $\operatorname{Var}{ }^{\circledR}$ had no effect on odour learning using the standard proboscis extension reflex assay but impaired the olfactory memory of bees for a short period of time after its introduction in the hive (Bonnafé et al. 2017). The formulation Apiguard ${ }^{\circledR}$ has been found to change the hygienic behaviours associated with olfactory cues shortly after its introduction in the hive (Colin et al. 2019c). Further research is needed to understand how thymol causes these complex effects on visual learning, olfactory memory, and behaviours linked to olfactory cues.

Our research adds to the evidence that miticides are not completely benign for honey bees. Beekeepers could immediately reduce any risks from using chemical miticide treatments by using non-chemical alternatives instead. Non-chemical approaches to the control of $V$. destructor include mechanical and behavioural control methods, and the selection of hygienic or resistant bee lines to control $V$. destructor. At present, there has not been enough research towards the development of non-chemical alternatives for the control of $V$. destructor (Dietemann et al. 2012; Meikle et al. 2012; Alquisira-Ramírez et al. 2017). The development of such methods would remove the risks of potential additive or synergistic interactions between miticides and other agricultural pesticides, and would improve honey bee health worldwide.

\section{ACKNOWLEDGEMENTS}

We thank Brian Entler and Hugo Baglan for their technical help with the learning chambers. 


\section{AUTHOR CONTRIBUTIONS}

Designed study: ABB, TC, JP, SK. Gathered data: TC, JP, SK, PV. Analysed data: TC, ABB, JP, SK, WGM. Wrote manuscript: TC, ABB, J-MD, ML, WGM, JP, SK, PV. Developed manuscript: TC, ABB, SK, JAP, PV, ML, J-MD, WGM.

\section{FUNDING INFORMATION}

SK was funded by a $\mathrm{PhD}$ fellowship from the French Ministry of Research and SK, JAP, and TC received an iMQRES scholarship from Macquarie University. JAP was funded by a DAAD Doktorandenstipendium awarded by the German Academic Exchange Service. JAP is currently supported by the German Research Foundation (DFG Priority Program 2041 "Computational Connectomics" and STE531/26-1). ABB is funded by the Australian Research Council (ARC Future Fellowship no. 140100452) and $\mathrm{ABB}$ and WGM by the United States Department of Agriculture ARS agreement no: 58-5342-3004F. JMD is funded by the Agence Nationale de la Recherche (ANR-13-ADAP-0002). ML is funded by the CNRS and the Agence Nationale de la Recherche (ANR-16-CE02-0002-01).

Le thymol, un acaricide, combiné à des traces d'imidaclopride, un néonicotinoïde, réduit la performance d'apprentissage visuel des abeilles (Apis mellifera).

Thymol / Varroa destructor / tau-fluvalinate / imidaclopride / acaricide.

Das Mitizid Thymol reduziert in Verbindung mit Spuren des Neonikotinoids Imidacloprid die visuellen Lernfähigkeit von Honigbienen (Apis mellifera).

Thymol / Varroa destructor / Tau-Fluvalinat / Imidacloprid / Akarizid.

\section{REFERENCES}

Alayrangues, J., Hotier, L., Massou, I., Bertrand, Y., \& Armengaud, C. (2016) Prolonged effects of in-hive monoterpenoids on the honey bee Apis mellifera . Ecotoxicology 25 (5),856-862.
Alburaki, M., Chen, D., Skinner, J. A., Meikle, W. G., Tarpy, D. R., Adamczyk, J., \& Stewart, S. D. (2018) Honey Bee Survival and Pathogen Prevalence: From the Perspective of Landscape and Exposure to Pesticides. Insects, 9 (2).

Alquisira-Ramírez, E. V., Peña-Chora, G., HernándezVelázquez, V. M., Alvear-García, A., Arenas-Sosa, I., Suarez-Rodríguez, R. (2017) Effects of Bacillus thuringiensis strains virulent to Varroa destructor on larvae and adults of Apis mellifera . Ecotoxicol. Environ. Saf. 142, 69-78.

Bates, D., Maechler, M., Bolker, B., Walker, S. (2015) Fitting Linear Mixed-Effects Models Using lme4. Journal of Statistical Software 67 (1), 1-48.

Berry, J. A., Hood, W. M., Pietravalle, S., Delaplane, K. S. (2013) Field-level sublethal effects of approved bee hive chemicals on honey bees (Apis mellifera L). PLoS One 8 (10), e76536.

Boecking, O., Spivak, M. (1999) Behavioral defenses of honey bees against Varroa jacobsoni Oud. Apidologie 30 (2-3), 141-158.

Bogdanov, S., Imdorf, A., Kilchenmann, V. (1998) Residues in wax and honey after Apilife VAR $®$ treatment. Apidologie 29 (6), 513-524.

Bonmatin, J. M., Marchand, P. A., Charvet, R., Moineau, I., Bengsch, E. R., Colin, M. E. (2005) Quantification of imidacloprid uptake in maize crops. J. Agric. Food. Chem. 53 (13), 5336-5341.

Bonnafé, E., Alayrangues, J., Hotier, L., Massou, I., Renom, et al. (2017) Monoterpenoid-based preparations in beehives affect learning, memory, and gene expression in the bee brain. Environ. Toxicol. Chem. 36 (2), 337-345.

Boyle, N. K., Sheppard, W. S. (2017) A scientific note on seasonal levels of pesticide residues in honey bee worker tissues. Apidologie 48 (1), 128-130.

Brodschneider, R., Brus, J., Danihlík, J. (2019) Comparison of apiculture and winter mortality of honey bee colonies (Apis mellifera) in Austria and Czechia. Agr. Ecosyst. Environ. 274, 24-32.

Calatayud-Vernich, P., Calatayud, F., Simó, E., Picó, Y. (2018) Pesticide residues in honey bees, pollen and beeswax: Assessing beehive exposure. Environ. Pollut. 241, 106-114.

Carayon, J.L., Téné, N., Bonnafé, E., Alayrangues, J., Hotier, L., Armengaud, C., Treilhou, M. (2014) Thy$\mathrm{mol}$ as an alternative to pesticides: persistence and effects of Apilife Var on the phototactic behavior of the honeybee Apis mellifera . Environ. Sci. Pollut. Res. Int. 21 (7), 4934-4939.

Colin, T., Meikle, W.G., Paten, A.M., Barron, A.B. (2019a) Long-term dynamics of honey bee colonies following exposure to chemical stress. Sci. Total Environ. 677, 660-670.

Colin, T., Meikle, W.G., Wu, X., Barron, A.B. (2019b) Traces of a Neonicotinoid Induce Precocious Foraging and Reduce Foraging Performance in Honey Bees. Environ. Sci. Technol. 53 (14), 8252-8261. 
Colin, T., Meng, Y. L., Quarrell, S. R., Allen, G. R., Barron, A. B. (2019c) Effects of thymol on European honey bee hygienic behaviour. Apidologie. 50 (2), 141-152.

Davies, T. G. E., Field, L. M., Usherwood, P. N. R., Williamson, M. S. (2007) DDT, pyrethrins, pyrethroids and insect sodium channels. IUBMB life, 59 (3), 151162.

Dietemann, V., Pflugfelder, J., Anderson, D., Charrière, J.D., Chejanovsky, N., et al. (2012) Varroa destructor: research avenues towards sustainable control. J. Apic. Res. 51 (1), 125-132.

Forfert, N., Troxler, A., Retschnig, G., Gauthier, L., Straub, L., et al. (2017) Neonicotinoid pesticides can reduce honeybee colony genetic diversity. PLoS One 12 (10), e0186109.

Frost, E. H., Shutler, D., \& Hillier, N. K. (2013) Effects of fluvalinate on honey bee learning, memory, responsiveness to sucrose, and survival. J. Exp. Biol. jeb086538 .

Gauthier, M. (2010). State of the art on insect nicotinic in learning and memory. In Insect Nicotinic Acetylcholine Receptors. Springer, New York, pp. 97-115.

Haarmann, T., Spivak, M., Weaver, D., Weaver, B., Glenn, T. (2002) Effects of fluvalinate and coumaphos on queen honey bees (Hymenoptera: Apidae) in two commercial queen rearing operations. J. Econ. Entomol. 95 (1), 28-35.

Henry, M., Beguin, M., Requier, F., Rollin, O., Odoux, J. F., et al. (2012) A common pesticide decreases foraging success and survival in honey bees. Science $\mathbf{3 3 6}$ (6079), 348-350.

Kirkerud, N. H., Wehmann, H.-N., Galizia, C. G., Gustav, D. (2013) APIS-a novel approach for conditioning honey bees. Front. Behav. Neurosci. 7, 29.

Klein, S., Cabirol, A., Devaud, J. M., Barron, A. B., Lihoreau, M. (2017) Why bees are so vulnerable to environmental stressors. Trends Ecol. Evol. 32 (4), 268-278.

Le Conte, Y., Ellis, M., Ritter, W. (2010) Varroa mites and honey bee health: can Varroa explain part of the colony losses? Apidologie 41 (3), 353-363.

Lenth, R. (2018) emmeans: Estimated Marginal Means, aka Least-Squares Means. R package version 1.3.0. https:/CRAN.R-project.org/package = emmeans

Lu, C., Warchol, K. M., Callahan, R. A. (2012) In situ replication of honey bee colony collapse disorder. B. Insectol. 65 (1), 99-106.

Meikle, W. G., Sammataro, D., Neumann, P., Pflugfelder, J. (2012) Challenges for developing pathogen-based biopesticides against Varroa destructor (Mesostigmata: Varroidae). Apidologie 43 (5), 501-514.

Meikle, W. G., Adamczyk, J. J., Weiss, M., Gregorc, A., Johnson, D. R., et al. (2016) Sublethal effects of imidacloprid on honey bee colony growth and activity at three sites in the US. PLoS One 11 (12), e0168603.

Mitchell, E. A., Mulhauser, B., Mulot, M., Mutabazi, A., Glauser, G., Aebi, A. (2017) A worldwide survey of neonicotinoids in honey. Science 358 (6359), 109111.

Mondet, F., Goodwin, M., Mercer, A. (2011) Age-related changes in the behavioural response of honeybees to Apiguard $\AA$, a thymol-based treatment used to control the mite Varroa destructor. J. Comp. Physiol. A 197 (11), 1055.

Mullin, C. A., Frazier, M., Frazier, J. L., Ashcraft, S., Simonds, R., Pettis, J. S. (2010) High levels of miticides and agrochemicals in North American apiaries: implications for honey bee health. PLoS One 5 (3), e9754.

Plath, J. A., Entler, B. V., Kirkerud, N. H., Schlegel, U., Galizia, C. G., Barron, A. B. (2017) Different roles for honey bee mushroom bodies and central complex in visual learning of colored lights in an aversive conditioning assay. Front. Behav. Neurosci. 11, 98.

Prado, A., Pioz, M., Vidau, C., Requier, F., Jury, et al. (2019) Exposure to pollen-bound pesticide mixtures induces longer-lived but less efficient honey bees. Sci. Total. Environ. 650, 1250-1260.

Price, K.L., Lummis, S.C. (2014) An atypical residue in the pore of Varroa destructor GABA-activated RDL receptors affects picrotoxin block and thymol modulation. Insect Biochem. Molec. Biol. 55 (1), 19-25.

R Core Team (2018) R: A language and environment for statistical computing. R Foundation for Statistical Computing, Vienna, Austria. URL: https:/www.Rproject.org/

Ratnieks, F. L., Carreck, N. L. (2010) Clarity on honey bee collapse? Science 327 (5962), 152-153.

Ray, D. E., Fry, J. R. (2006) A reassessment of the neurotoxicity of pyrethroid insecticides. Pharmacol. Ther. 111 (1), 174-193.

Rosenkranz, P., Aumeier, P., Ziegelmann, B. (2010) Biology and control of Varroa destructor. J. Invertebr. Pathol. 103, S96-S119.

Sánchez-Bayo, F., Goulson, D., Pennacchio, F., Nazzi, F., Goka, K., Desneux, N. (2016) Are bee diseases linked to pesticides? A brief review. Environ. Int. 89, 7-11.

Sgolastra, F., Medrzycki, P., Bortolotti, L., Renzi, M. T., Tosi, S., et al. (2017) Synergistic mortality between a neonicotinoid insecticide and an ergosterolbiosynthesis-inhibiting fungicide in three bee species. Pest. Manag. Sci. 73 (6), 1236-1243.

Sgolastra, F., Arnan, X., Cabbri, R., Isani, G., Medrzycki, P., Teper, D., Bosch, J. (2018) Combined exposure to sublethal concentrations of an insecticide and a fungicide affect feeding, ovary development and longevity in a solitary bee. Proc. Biol. Sci. 285 (1885), 20180887.

Simon-Delso, N., Amaral-Rogers, V., Belzunces, L.P., Bonmatin, J.M., Chagnon, et al. (2015) Systemic insecticides (neonicotinoids and fipronil): trends, uses, mode of action and metabolites. Environ. Sci. Pollut. Res. 22 (1), 5-34.

Taylor-Wells, J., Brooke, B. D., Bermudez, I., Jones, A. K. (2015) The neonicotinoid imidacloprid, and the 
pyrethroid deltamethrin, are antagonists of the insect Rdl GABA receptor. J. Neurochem. 135 (4), 705-713.

Tihelka, E. (2018). Effects of synthetic and organic acaricides on honey bee health: A review. Slov. Vet. Res. 55 (3), 114-140.

Tosi, S., Burgio, G., Nieh, J. C. (2017) A common neonicotinoid pesticide, thiamethoxam, impairs honey bee flight ability. Sci. Rep. 7 (1), 1201.

Tosi, S., Costa, C., Vesco, U., Quaglia, G., Guido, G. (2018) A 3-year survey of Italian honey bee-collected pollen reveals widespread contamination by agricultural pesticides. Sci. Total. Environ. 615, 208-218.

Tsigouri, A.D., Menkissoglu-Spiroudi, U., Thrasyvoulou, A. (2001) Study of tau-fluvalinate persistence in honey. Pest Manag. Sci. 57 (5), 467-471.

Tsvetkov, N., Samson-Robert, O., Sood, K., Patel, H. S., Malena, D. A., et al. (2017) Chronic exposure to neonicotinoids reduces honey bee health near corn crops. Science 356 (6345), 1395-1397.

Urlacher, E., Frances, B., Giurfa, M., Devaud, J.M. (2010) An alarm pheromone modulates appetitive olfactory learning in the honeybee (Apis mellifera). Front. Behav. Neurosci. 4, 1-10.
Wallner, K., Fries, I. (2003) Control of the mite Varroa destructor in honey bee colonies. Pestic. Outlook 14 (2), 80-84.

Wickham, H. (2016) ggplot2: Elegant graphic design for data analysis, Springer-V. ed. Springer-Verlag New York, New York.

Wilke, C.O. (2019) cowplot: Streamlined Plot Theme and Plot Annotations for "ggplot2." URL: https://cran.rproject.org/package $=$ cowplot

Winston, M. L. L. (1991) The biology of the honey bee. Harvard University Press.

Woodcock, B. A., Bullock, J. M., Shore, R. F., Heard, M. S., Pereira, M. G., et al. (2017) Country-specific effects of neonicotinoid pesticides on honey bees and wild bees. Science 356 (6345), 1393-1395.

Zhou, T., Zhou, W., Wang, Q., Dai, P. L., Liu, F., Zhang, Y. L., Sun, J. H. (2011) Effects of pyrethroids on neuronal excitability of adult honeybees Apis mellifera. Pest. Biochem. Physiol. 100 (1), 35-40.

Publisher's note Springer Nature remains neutral with regard to jurisdictional claims in published maps and institutional affiliations. 